\title{
Do green-blocking glasses enhance the nonvisual effects of white polychromatic light?
}

\author{
Soomin Lee ${ }^{1 *} \mathbb{D}$, Naoshi Kakitsuba ${ }^{2}$ and Tetso Katsuura ${ }^{3}$
}

\begin{abstract}
Background: It is well known that light containing the blue component stimulates the intrinsically photosensitive retinal ganglion cells (ipRGCs) and plays a role in melatonin suppression and pupillary constriction. In our previous studies, we verified that simultaneous exposure to blue and green light resulted in less pupillary constriction than blue light exposure. Hence, we hypothesized that the nonvisual effects of polychromatic white light might be increased by blocking the green component. Therefore, we conducted an experiment using optical filters that blocked blue or green component and examined the nonvisual effects of these lights on pupillary constriction and electroencephalogram power spectra.
\end{abstract}

Methods: Ten healthy young males participated in this study. The participant sat on a chair with his eyes facing an integrating sphere. After 10 min of light adaptation, the participant's left eye was exposed to white pulsed light (1000 lx; pulse width $2.5 \mathrm{~ms}$ ) every $10 \mathrm{~s}$ with a blue-blocking glasses, a green-blocking glasses, or control glasses (no lens), and pupillary constriction was measured. Then, after rest for $10 \mathrm{~min}$, the participant was exposed a continuous white light of $1000 \mathrm{~lx}$ with a blue- or green-blocking glasses or control glasses and electroencephalogram was measured.

Results: Pupillary constriction with the blue-blocking glasses was significantly less than that observed with the green-blocking glasses. Furthermore, pupillary constriction under the green-blocking glasses was significantly greater than that observed with the control glasses.

Conclusions: A reduction in the green component of light facilitated pupillary constriction. Thus, the effects of polychromatic white light containing blue and green components on ipRGCs are apparently increased by removing the green component.

Keywords: Blue-blocking glasses, Green-blocking glasses, ipRGCs, Subadditive response, Nonvisual response

\section{Background}

Humans adapted slowly for seven million years under sunlight, until the artificial light was invented. As modern technology has progressed, the artificial light has become unavoidable in a variety of situations. Accordingly, night-shift work and use of portable devices at nighttime have increased rapidly, such that humans are exposed to light, regardless of the time of day or night. Light that contains the blue component stimulates intrinsically

\footnotetext{
*Correspondence: yisoomin@chiba-u.jp

${ }^{1}$ Center for Environment, Health and Sciences, Chiba University, Kashiwa, Japan

Full list of author information is available at the end of the article
}

photosensitive retinal ganglion cells (ipRGCs) and contributes to melatonin suppression $[1,2]$ and pupillary constriction [3-7]. Critically, blue light exposure in the evening induces sleep disturbances, transient eye discomfort, and headaches $[8,9]$. In particular, it has been reported that the blue light emitted directly from computer displays suppresses melatonin secretion during the night $[10,11]$ and that the use of blue-blocking glasses inhibits this action [11-14]. Conversely, daytime blue light exposure has an acute preventive impact on light-induced melatonin suppression at night [15]. Furthermore, chronic daytime exposure to blue-enriched

(c) The Author(s). 2018 Open Access This article is distributed under the terms of the Creative Commons Attribution 4.0 International License (http://creativecommons.org/licenses/by/4.0/), which permits unrestricted use, distribution, and reproduction in any medium, provided you give appropriate credit to the original author(s) and the source, provide a link to the Creative Commons license, and indicate if changes were made. The Creative Commons Public Domain Dedication waiver (http://creativecommons.org/publicdomain/zero/1.0/) applies to the data made available in this article, unless otherwise stated. 
light has the potential to improve the subjective measures of alertness, concentration, and eye discomfort [9].

However, Figueiro et al. [16] found that simultaneous exposure to blue and green light resulted in reduced melatonin suppression, compared with monochromatic light exposure to blue or green light; this was referred to as a subadditive response to light. We also verified that simultaneous blue and green light exposure resulted in less pupillary constriction than blue light exposure [6, 7]. These findings indicated that the effect of blue light was inhibited by simultaneous exposure to green light. In addition, the melatonin suppression response to polychromatic white light was significantly lower than to monochromatic blue light $[17,18]$.

Hence, we hypothesized that the nonvisual effects of polychromatic white light might increase by blocking the green component. Therefore, we conducted a novel experiment by using optical filters that blocked the blue or green components and examined the nonvisual effects of light on pupillary constriction and electroencephalogram power spectra.

\section{Main text \\ Study participants}

Ten healthy young males $(22 \pm 0.5$ years, $174.4 \pm 3.6 \mathrm{~cm}$, $63.2 \pm 5.2 \mathrm{~kg}$ ) with normal color vision participated in the experiment. Written informed consent was obtained from all subjects after a full explanation of the experimental purpose and protocol. This experiment was approved by the Ethics Committee of the Graduate School of Horticulture, Chiba University (\#15-06).

\section{Lighting condition and transmittance of glasses}

We used white-pulsed LED light (1000 lx, pulse width 2.5 ms; 16 W24-AW2S, Kashinoki Sogyo Co., LTD.) for measuring pupillary constriction according to our previous studies [5-7] and white-continuous LED light (1000 lx) for electroencephalogram (EEG) measurement with white background light (100 lx), by using an integrating sphere (Takano Co., Nagano, Japan). We used a background light in order to saturate rods responses [19] and avoid the influence of rods on pupillary contraction as much as possible [7]. The illuminance of light was measured at each subject's eye level by using a spectroradiometer (CL-500A, Konica Minolta Optics Co., Tokyo, Japan). The experiment was conducted in a climatic chamber in which the air temperature and relative humidity were set at $25{ }^{\circ} \mathrm{C}$ and $50 \%$, respectively. Each participant wore blue-blocking glasses, green-blocking glasses, and control glasses (no lens) in each condition, respectively. These glasses contained only left-side lenses in order to measure the pupillary diameter (PD) of the right eye (Fig. 1a). Figure 1b, c show the spectral transmittance of these glasses and irradiance of the source white LED light and of the light through the blue-blocking and green-blocking glasses. Table 1 summarizes the relevant photometric measures of the source white LED light and of the light through each set of glasses [20].

\section{Procedure and measurements}

Each participant sat on a chair with his eyes facing the integrating sphere. Only his left eye was exposed to the light through the glasses, while his right eye faced the electronic pupillometer (FP-10000II, TMI, Tokyo, Japan). Each participant completed four steps of the experiment as follows: 10 min of background light exposure for light adaptation, pupil diameter measurement during pulsed light exposure, rest for $10 \mathrm{~min}$, and EEG measurement at $\mathrm{Fz}, \mathrm{Cz}$, and $\mathrm{Pz}$ (Biopac Systems, CA, USA) under continuous LED light exposure. In the measurement of pupil diameter, each participant's left eye was exposed nine times to the pulsed light every $10 \mathrm{~s}$. This process was repeated three times for each of the three glasses conditions. Pupil diameter measurements were averaged for each subject and under each glasses condition. In the measurement of EEG, each participant underwent 6 min of Alpha Attenuation Test (AAT) and 4 min of EEG measurement to determine the alpha-band ratio (alpha-band power/(alpha-band power + beta-band power $) \times 100$ ) under continuous LED light. This process was repeated three times for each of the three glasses conditions. Figure 2 shows a schematic of the experiment.

From the measurement of PD, we calculated the pupillary constriction ratio (\% pupillary constriction) as follows: \% pupillary constriction $=[$ (baseline $P D-$ minimum PD after light exposure)/baseline PD] $\times 100$.

\section{Statistical analysis}

We used one-way repeated measures analysis of variance (ANOVA) (SPSS Statistics Ver. 21, IBM, Armonk, NY, USA) to evaluate the effects of the glasses factor on pupillary constriction. Two-way repeated measures ANOVA (glasses factor $\times$ region factor) was conducted on EEG measurements. When significant effects were found, multiple comparisons of the glasses condition were performed by the Bonferroni method.

\section{Results \\ Pupillary constriction}

In the $\%$ pupillary constriction, there is significant difference among three glasses conditions $[F(2,34)=15.6499$, $p=0.001]$. The $\%$ pupillary constriction in the blue-blocking glasses condition was significantly less than in the green-blocking condition. Furthermore, the $\%$ pupillary constriction in the green-blocking glasses condition, which contained the blue component of light but less green component, was significantly greater than the control glasses condition, which contained both blue and green components. There were no 
a

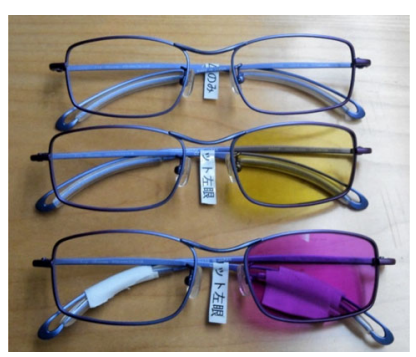

$\mathrm{C}$

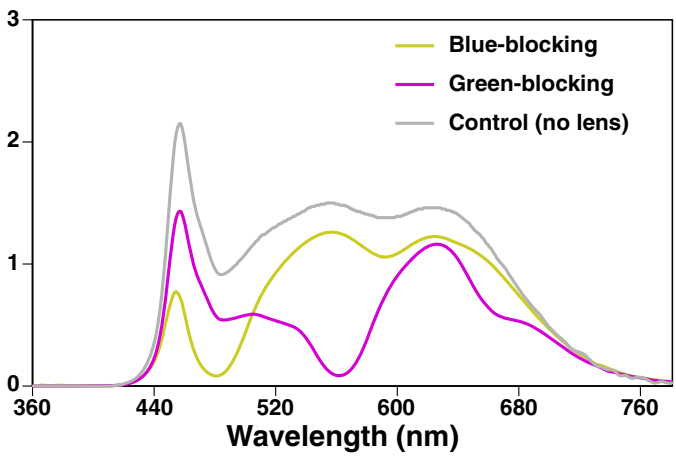

Fig. 1 a The control glasses, blue-blocking glasses, and green-blocking glasses are shown in order from the top. b Spectral transmittance of blueblocking glasses and green-blocking glasses. c Spectral irradiance of light of the source white LED light (no lens: control) and of the light through the blue-blocking and green-blocking glasses

significant differences between the \% pupillary constriction in the blue-blocking glasses condition and the control glasses condition (Fig. 3).

\section{Electroencephalogram}

There were no significant differences in Alpha Attenuation Coefficient (AAC) $[F(2,18)=0.2709(\mathrm{Fz})$, $F(2,18)=0.0135(\mathrm{Cz}), \quad F(2,18)=0.48858(\mathrm{Pz})]$ and alpha-band ratio $[F(2,18)=2.1369(\mathrm{Fz}), \quad F(2,18)=$
$2.1058(\mathrm{Cz}), F(2,18)=1.2104(\mathrm{Pz})]$ among the three glasses conditions (Fig. 4).

\section{Conclusions}

In this study, we could not find any differences in AAC and alpha-band ratio among the three glasses conditions. We measured EEG during 10 min period for each glasses condition. It might be too short to make any differences in arousal level and EEG activity.

Table 1 Characteristics of the light through each glasses conditions

\begin{tabular}{llll}
\hline Glasses condition & Blue-blocking & Green-blocking & Control (no lens) \\
\hline Irradiance $\left(\mu \mathrm{W} / \mathrm{cm}^{2}\right)$ & 240 & 184 & 345 \\
Photon density $\left(10^{12}\right.$ photons $\left./ \mathrm{cm}^{2} / \mathrm{s}\right)$ & 716 & 537 & 988 \\
Photon density (log photons $\left./ \mathrm{cm}^{2} / \mathrm{s}\right)$ & 14.9 & 14.7 & 15.0 \\
Photopic illuminance (Ix) & 770 & 376 & 1008 \\
Scotopic illuminance (Ix) & 1070 & 922 & 2025 \\
Cyanopic IX (S-cone) & 202 & 397 & 611 \\
Melanopic IX (Melanopsin) & 377 & 445 & 860 \\
Rhodopic Ix (Rod) & 494 & 396 & 903 \\
Chloropic Ix (M-cone) & 654 & 363 & 965 \\
Erythropic IX (L-cone) & 732 & 412 & 988 \\
\hline
\end{tabular}




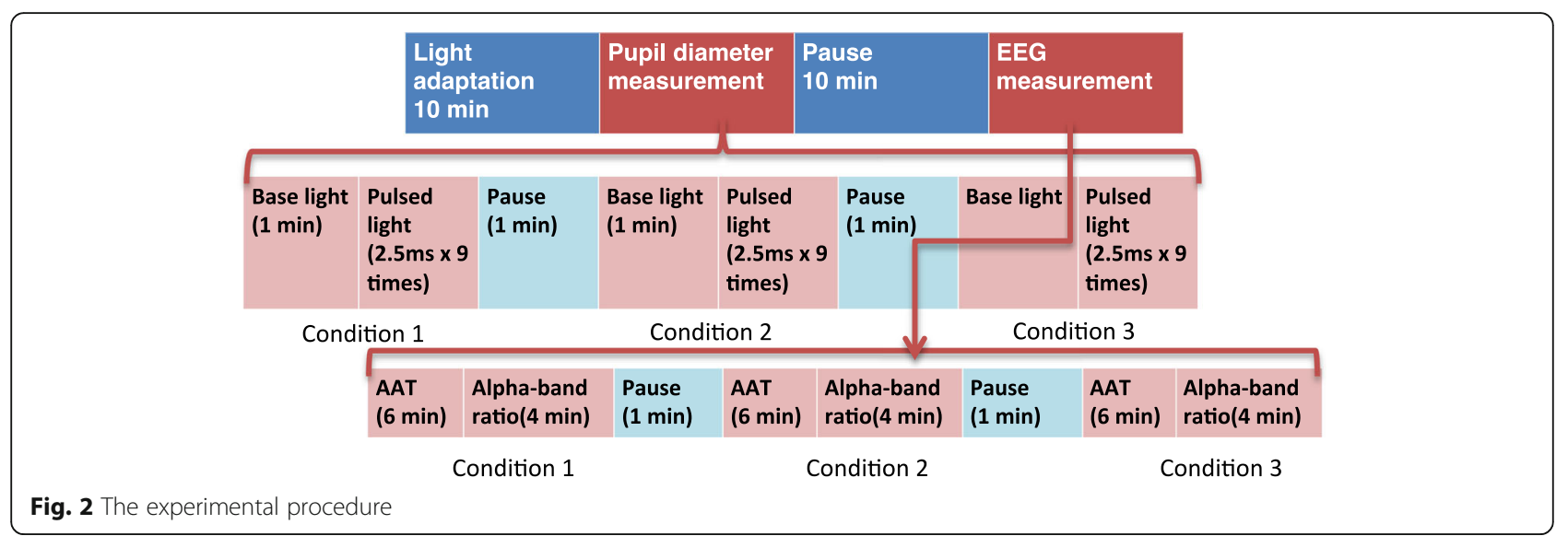

We found that the pupillary constriction in the blue-blocking glasses condition was less than in the green-blocking glasses condition. It might be inferred from the characteristics of ipRGCs that pupillary constriction in the blue-blocking glasses condition, which allowed minimal transmittance of the blue component of light, was markedly suppressed, compared with the green-blocking glasses condition, which allowed high transmittance of the blue component of light. Moreover, the most important finding was that pupillary constriction in the green-blocking glasses condition was significantly greater than in the control glasses condition, although the green-blocking glasses allowed approximately half the melanopic illuminance of the control glasses, as shown in Table 1.

It has been suggested that cone-derived color signals may influence nonvisual responses to light, such as pupillary light responses [21]. Woelders et al. [21] have demonstrated that $\mathrm{M}$ - and S-cones provide inhibitory input to the pupillary control system, whereas L-cones and melanopsin response present an excitatory role. These findings support a subadditive response to light, where the effects of blue light are reduced by green or polychromatic light exposure, as in the previous studies [6, 7] and the present study.

We also found that the pupillary constriction in the blue-blocking glasses and the control condition were almost same. We also hypothesized that the responses of ipRGCs might be reduced by inhibition from cones on simultaneous exposure to blue and green light in the control condition and might result in the same responses in the blue-blocking glasses condition, which had less blue component by nature.

Thus, the effects of polychromatic light, which contained blue and green components, on ipRGCs are apparently increased by removing the green component, as

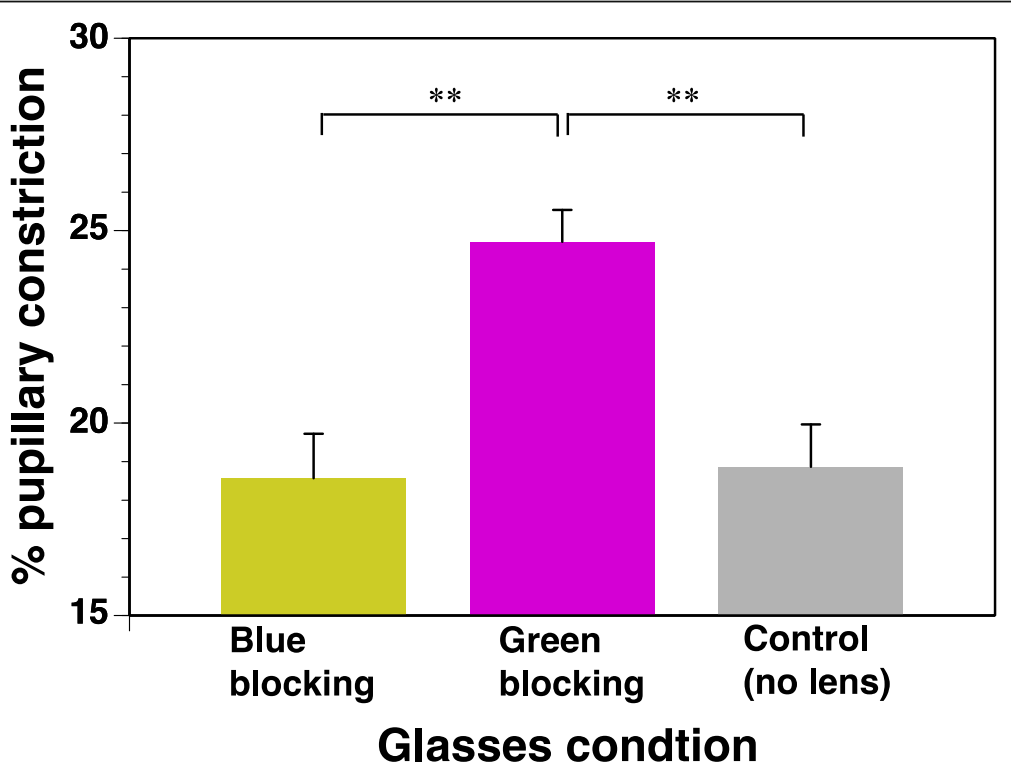

Fig. 3 Pupillary constriction in three glasses conditions (means \pm S.E., $n=10,{ }^{* *} p<0.01$ ) 
a

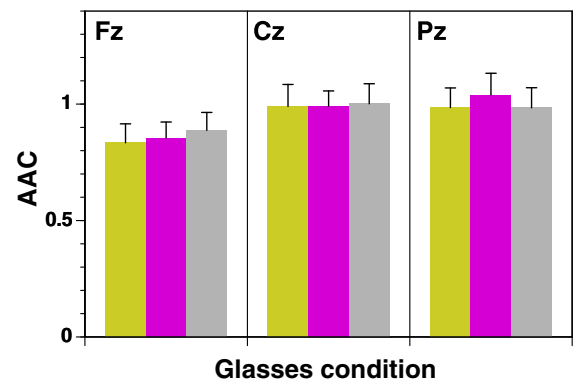

$\mathrm{b}$

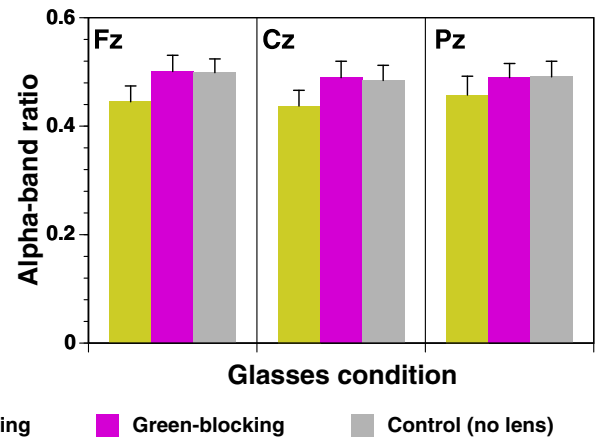

Fig. 4 a Alpha Attenuation Test (AAT) and $\mathbf{b}$ alpha-band ratio in three glasses conditions at Fz, Cz, and Pz (means \pm S.E., $n=10$ )

shown by using the green-blocking glasses in the present study. In addition, blue light exposure during the daytime improved nocturnal light-induced melatonin suppression [15]. If always wearing light-blocking lenses, adaptation to the changes in the spectral composition of light occurs [22]. However, such adapting effect does not occur in wearing glasses for several hours a day, and effective improvements can be expected [23]. Therefore, the use of green-blocking glasses during the daytime for several hours might improve these nonvisual effects.

In conclusion, the nonvisual effects of polychromatic white light were increased by blocking the green component of light. Therefore, we propose that the use of green-blocking glasses during the daytime for several hours might expand nonvisual effects (e.g., high arousal level) in the daytime and may improve nighttime sleep quality.

\section{Abbreviations}

AAC: Alpha Attenuation Coefficient; AAT: Alpha Attenuation Test: ANOVA: Analysis of variance; EEG: Electroencephalogram; ipRGCs: Intrinsically photosensitive retinal ganglion cells; PD: Pupillary diameter

\section{Acknowledgements}

We would like to thank Mr. Tetsuya Takeuchi who willingly contributed in this study.

\section{Funding}

This work was supported by ITOH Optical Industrial Co., Ltd.

\section{Availability of data and materials}

The datasets during the current study are available from the corresponding author on reasonable request.

\section{Authors' contributions}

SL wrote the manuscript. SL carried out this experiment and analyzed the data. SL and TK conceived of the study. SL, NK, and TK were responsible for coordination of the study and overseeing data collection and analysis. All authors have read and approved the final the manuscript.

\section{Ethics approval and consent to participate}

This experiment was approved by the bioethics committee of the Graduate School of Horticulture, Chiba University.
Consent for publication

All participants gave written informed consent for publication after a complete explanation of this study.

\section{Competing interests}

The sponsor had no control over the writing or publication of this work. The authors declare that they have no competing interests.

\section{Publisher's Note}

Springer Nature remains neutral with regard to jurisdictional claims in published maps and institutional affiliations.

\section{Author details}

${ }^{1}$ Center for Environment, Health and Sciences, Chiba University, Kashiwa, Japan. ${ }^{2}$ Faculty of Science and Technology, Meijo University, Nagoya, Japan. ${ }^{3}$ Graduate School of Engineering, Chiba University, Chiba, Japan.

Received: 3 August 2018 Accepted: 4 December 2018

Published online: 18 December 2018

\section{References}

1. Brainard GC, Sliney D, Hanifin JP, Glickman G, Byrne B, Greeson JM, Jasser S, Gerner E, Rollag MD. Sensitivity of the human circadian system to shortwavelength (420-nm) light. J Biol Rhythm. 2008;23:379-86.

2. Kozaki T, Kubokawa A, Taketomi R, Hatae K. Effects of day-time exposure to different light intensities on light-induced melatonin suppression at night. J Physiol Anthropol. 2015;34:27.

3. Daneault V, Vandewalle G, Hebert M, Teikari P, Mure LS, Doyon J, Gronfier C, Cooper HM, Dumont M, Carrier J. Does pupil constriction under blue and green monochromatic light exposure change with age? J Biol Rhythm. 2012;27:257-64.

4. Güler AD, Ecker JL, Lall GS, Haq S, Altimus CM, Liao HW, Barnard AR, Cahill $\mathrm{H}$, Badea TC, Zhao H, et al. Melanopsin cells are the principal conduits for rod-cone input to non-image-forming vision. Nature. 2008;453:102-5.

5. Katsuura T, Ochiai Y, Senoo T, Lee S, Takahashi Y, Shimomura Y. Effects of blue pulsed light on human physiological functions and subjective evaluation. J Physiol Anthropol. 2012;31:23.

6. Lee S, Ishibashi S, Shimomura Y, Katsuura T. Effect of simultaneous exposure to extremely short pulses of blue and green light on human pupillary constriction. J Physiol Anthropol. 2016;35:20.

7. Lee S, Uchiyama Y, Shimomura Y, Katsuura T. Subadditive responses to extremely short blue and green pulsed light on visual evoked potentials, pupillary constriction and electroretinograms. J Physiol Anthropol. 2017;36:39

8. van der Lely S, Frey S, Garbazza C, Wirz-Justice A, Jenni OG, Steiner R, Wolf S, Cajochen C, Bromundt V, Schmidt C. Blue blocker glasses as a countermeasure for alerting effects of evening light-emitting diode screen exposure in male teenagers. J Adolesc Health. 2015:56:113-9.

9. Viola AU, James LM, Schlangen LJ, Dijk DJ. Blue-enriched white light in the workplace improves self-reported alertness, performance and sleep quality. Scand J Work Environ Health. 2008;34:297-306. 
10. Chang AM, Aeschbach D, Duffy JF, Czeisler CA. Evening use of lightemitting eReaders negatively affects sleep, circadian timing, and nextmorning alertness. Proc Natl Acad Sci U S A. 2015;112:1232-7.

11. Figueiro MG, Wood B, Plitnick B, Rea MS. The impact of light from computer monitors on melatonin levels in college students. Neuro Endocrinol Lett. 2011;32:158-63.

12. Burkhart K, Phelps JR. Amber lenses to block blue light and improve sleep: a randomized trial. Chronobiol Int. 2009;26:1602-12.

13. Sasseville A, Hebert M. Using blue-green light at night and blue-blockers during the day to improves adaptation to night work: a pilot study. Prog Neuro-Psychopharmacol Biol Psychiatry. 2010;34:1236-42.

14. Sasseville A, Paquet N, Sevigny J, Hebert M. Blue blocker glasses impede the capacity of bright light to suppress melatonin production. J Pineal Res. 2006;41:73-8.

15. Kozaki T, Kubokawa A, Taketomi R, Hatae K. Light-induced melatonin suppression at night after exposure to different wavelength composition of morning light. Neurosci Lett. 2016;616:1-4.

16. Figueiro MG, Bierman A, Rea MS. Retinal mechanisms determine the subadditive response to polychromatic light by the human circadian system. Neurosci Lett. 2008;438:242-5.

17. Figueiro MG, Bullough JD, Parsons RH, Rea MS. Preliminary evidence for spectral opponency in the suppression of melatonin by light in humans. Neuroreport. 2004;15:313-6.

18. Revell VL, Barrett DC, Schlangen LJ, Skene DJ. Predicting human nocturnal nonvisual responses to monochromatic and polychromatic light with a melanopsin photosensitivity function. Chronobiol Int. 2010;27:1762-77.

19. Fukuda Y, Tsujimura S, Higuchi S, Yasukouchi A, Morita T. The ERG responses to light stimuli of melanopsin-expressing retinal ganglion cells that are independent of rods and cones. Neurosci Lett. 2010;479:282-6.

20. Lucas RJ, Peirson SN, Berson DM, Brown TM, Cooper HM, Czeisler CA, Figueiro MG, Gamlin PD, Lockley SW, O'Hagan JB, et al. Measuring and using light in the melanopsin age. Trends Neurosci. 2014;37:1-9.

21. Woelders T, Leenheers T, Gordijn MCM, Hut RA, Beersma DGM, Wams EJ. Melanopsin- and L-cone-induced pupil constriction is inhibited by S- and M-cones in humans. Proc Natl Acad Sci U S A. 2018:115:792-7.

22. Gimenez MC, Beersma DG, Bollen P, van der Linden ML, Gordijn MC. Effects of a chronic reduction of short-wavelength light input on melatonin and sleep patterns in humans: evidence for adaptation. Chronobiol Int. 2014;31: 690-7.

23. Esaki Y, Kitajima T, Ito Y, Koike S, Nakao Y, Tsuchiya A, Hirose M, Iwata N. Wearing blue light-blocking glasses in the evening advances circadian rhythms in the patients with delayed sleep phase disorder: an open-label trial. Chronobiol Int. 2016;33:1037-44.

Ready to submit your research? Choose BMC and benefit from:

- fast, convenient online submission

- thorough peer review by experienced researchers in your field

- rapid publication on acceptance

- support for research data, including large and complex data types

- gold Open Access which fosters wider collaboration and increased citations

- maximum visibility for your research: over $100 \mathrm{M}$ website views per year

At $\mathrm{BMC}$, research is always in progress.

Learn more biomedcentral.com/submissions 